\title{
Biomusicalidade, Experiência e Awareness Coletiva: Gestalt-Terapia e Musicoterapia no Cuidado de Pais e Bebês
}

\section{Biomusicality, Experience e Collective Awareness: Gestalt- Therapy, Music Therapy in Parent and Baby Care}

\author{
Biomusicalidad, Experiencia y Awareness Colectiva: Terapia \\ Gestalt, Musicoterapia en el Cuidado de Padres y Bebés
}

\section{Paulo-de-Tarso de Castro Peixoto*}

Secretaria Adjunta de Ensino Superior - Universidade Livre - Prefeitura Municipal de Macaé, Macaé, Rio de Janeiro, Brasil

\begin{abstract}
RESUMO
O artigo apresenta caminhos sobre a produção do cuidado para pais e bebês. Inicialmente é apresentado o conceito de 'biomusicalidade', trazendo em cena a visão da vida tecida em contrapontos, a partir dos signos-sinais afetivos advindos das relações. As perspectivas da Gestalt-Terapia, da Musicoterapia e das Filosofias da Imanência sustentam as experiências de produção do cuidado para os pais e bebês. Problematiza-se a questão da produção de novas temporalidades nas relações entre os pais dirigida à produção do cuidado onde a subjetividade dos filhos seja 'afetada' por campos de experiências vitais. Experiências movidas pela potência do desejo da descoberta, da busca pela novidade, do desejo de conexão com algo do ambiente que possa nutrir. Experiências da potência do devir-criança que habita os adultos e que pode ser despertada pelos campos de afetação do espaço clínico. O artigo propõe o desenvolvimento de uma Scientia Patibilis Natura, como uma Ciência da Alma Sensível. Ciência aliançada a uma 'fenomenologia biomusical' que orienta e excita as consciências sensíveis dos pais para a produção de uma consciência sensível mutual, uma awareness coletiva. Experiências produtoras de um espaço clínico excitante, espaço da relação, espaço do sagrado, espaço da musicalidade da vida, espaço biomusical.
\end{abstract}

Palavras-chave: biomusicalidade, gestalt-terapia, musicoterapia, cuidado, pais e bebês.

\begin{abstract}
The article presents paths on the production of care for parents and babies. Initially, the concept of 'biomusicality' is presented, bringing into view the vision of life woven into counterpoints, based on the affective sign-signals arising from relationships. The perspectives of Gestalt-Therapy, Music Therapy, and the Immanence Philosophies support the care-producing experiences for parents and babies. The question of the production of new temporalities in the relations between the parents is problematized in order to produce care where the subjectivity of the children is 'affected' by fields of
\end{abstract}


vital experiences. Experiences that are driven by the power of the desire for discovery, the search for novelty, the desire to connect with something in the environment that can nurture; experiences of the power of the childdevir that inhabits adults and that can be awakened by the fields of affectation of the clinical space. The article proposes the development of a Scientia Patibilis Natura, as a Sensitive Soul Science. Science allied to a 'biomusical phenomenology' that guides and excites parents' sensible consciousnesses to produce a mutual sensible consciousness, a collective awareness. Experiences which produce an exciting clinical space, a space of relationship, a space of the sacred, a space of the musicality of life, a biomusical space.

Keywords: biomusicality, gestalt-therapy, music therapy, care, parents and babies.

\begin{abstract}
RESUMEN
El artículo presenta formas sobre la producción de cuidado para padres y bebés. Inicialmente se presenta el concepto de 'biomusicalidad', trayendo a escena la visión de la vida tejida en contrapuntos, a partir de los signosseñales afectivos provenientes de las relaciones. Las perspectivas de la Terapia Gestalt, la Musicoterapia y las Filosofías de la Inmanencia sostienen las experiencias de la producción del cuidado para padres y bebés. Se problematiza la cuestión de la producción de nuevas temporalidades en las relaciones entre padres y madres, con el fin de producir cuidados donde la subjetividad de los niños se 'afecta' por campos vitales de experiencia. Experiencias impulsadas por la potencia del deseo de descubrimiento, la búsqueda de la novedad, el deseo de conexión con algo en el entorno que puede nutrir. Experiencias de la potencia del devenir-niño que habita en los adultos y que se puede ser despertado por los campos de afectación del espacio clínico. El artículo propone el desarrollo de una Scientia Patibilis Natura como una Ciencia del Alma Sensible. Ciencia aliada a una 'fenomenología biomusical' que guía y excita las conciencias sensibles de los padres para la producción de una conciencia sensible mutua, una awareness colectiva. Experiencias que producen un estimulante espacio clínico, espacio de la relación, espacio de lo sagrado, espacio de la musicalidad de la vida, espacio biomusical.
\end{abstract}

Palabras clave: biomusicalidad, terapia gestalt, musicoterapia, cuidado, padres y bebés.

"O tempo do devir é o tempo do sentir." (Peixoto, 2018).

Este artigo apresenta pistas e caminhos para a promoção e o desenvolvimento do cuidado com os bebês, passando pelo processo de transformação das formas de marcar ritmos, pulsações e cadências das formas como os pais compõem as suas vidas. A vida de cada pessoa é feita a partir da biomusicalidade em que é capaz a cada encontro, a cada contato. Os movimentos, repousos, velocidades e lentidões dos desejos, dos afetos, das emoções, das suas escolhas, das direções que dá aos desejos, são marcados pela musicalidade da sua relação com a vida. Desenvolver as capacidades de fazer 'acordes' com aquilo que vem do seu mundo e com aquilo que vem do ambiente será poder habitar fronteiras inéditas de onde 
as 'terceiras histórias', ou seja, as histórias da relação, são construídas (Delacroix, 2006).

A experiência dimanada de uma temporalidade do sentir, acompanhada por uma 'consciência aware', advinda das formas como os pais compõem suas 'superfícies contatuais', poderia ser o prelúdio para a construção de espaços de relações vitais? Como desenvolver esta consciência afetiva, sensível e orientada ao cuidado dos pais e bebês? Quais seriam as condições para o desenvolvimento de um olhar mais sensível dos pais em suas formas de se contatarem, a partir de uma 'fenomenologia biomusical'? A construção de outras temporalidades no processo de formação de superfícies contatuais entre os pais poderia ter efeitos na subjetividade dos seus filhos? A construção de outras formas de marcar as temporalidades dos contatos poderia contribuir para a edificação de uma 'awareness coletiva' entre pais e bebês?

Estas questões serão desenvolvidas pelas perspectivas da GestaltTerapia, da Musicoterapia e das Filosofias da Imanência. Abordagens que são convidadas a habitarem juntas a superfície-fronteira, onde 0 cuidado entre pais e bebês é desenvolvido para o crescimento, a expansão, a descoberta, sempre inédita, de uma awareness coletiva biomusical.

\section{Biomusicalidade, 'potência crianceira' e ajustamentos criadores}

Cresci brincando no chão, entre formigas. De uma infância livre e sem comparamentos. Eu tinha mais comunhão com as coisas do que comparação. Porque se a gente fala a partir de ser criança, a gente faz comunhão: de um orvalho e sua aranha, de uma tarde e suas garças, de um pássaro e sua árvore. Então eu trago das minhas raízes crianceiras a visão comungante e oblíqua das coisas. Eu sei dizer sem pudor que o escuro me ilumina. É um paradoxo que ajuda a poesia e que eu falo sem pudor. Eu tenho que essa visão oblíqua vem de eu ter sido criança em algum lugar perdido onde havia transfusão da natureza e comunhão com ela. Era o menino e os bichinhos. Era o menino e o sol. O menino e o rio. Era o menino e as árvores. (Manoel de Barros, 2003, p. 53).

Fizemos o convite a Manoel de Barros para 'preludiar' esta primeira parte. E este convite não é sem propósito. Manoel nos instiga a olhar a vida como composições em contrapontos, a partir de uma visão de mundo 'crianceira'. Ele nos convida a sair do mundo das representações, da experiência de referir o que se vive no instante aqui-e-agora àquilo que já fora vivido anteriormente. Manoel nos 
'desconvida' ao olhar viciado dos 'comparamentos', propondo um olhar dirigido ao que se passa na nossa relação com os ambientes, no aqui-e-agora da experiência. Esse inusitado 'desconvite' é um convite à experiência e à perspectiva de uma vida como composição. Manoel nos convida ao apetite da curiosidade, da descoberta, a habitarmos fronteiras onde mundos estrangeiros nos instigam à saída dos nossos condicionamentos e repetições. 'Criançamos' quando passamos a fazer composições com as matérias-primas que estão disponíveis no aqui-e-agora da experiência, dando-lhes novas formas.

Esta visão de mundo 'crianceira' se liga diretamente ao que F. Perls, Hefferline e Goodman (1997) nos falam acerca da atividade das crianças: ". . . é a sensação vívida e a brincadeira irrestrita destas, aparentemente sem objetivo, que permite à energia fluir espontaneamente e chegar a semelhantes invenções fascinantes." ( $p$. 59). Decorre dessa 'dimensão crianceira' a expressão da potência existente em cada pessoa e que poderá ser desenvolvida através de experiências contatuais vitais: a potência-capacidade de dar novas formas ao que aparece diante de si, de reinventar e inventar novas maneiras de lidar com aquilo que vem do ambiente para a produção de 'acordes' com aquilo que vem de si (desejos, emoções, imagens, interesses-apetites, sensações...).

Abrir-se à vida como compositor-esteta de novos ajustamentos criadores se liga à tarefa fundamental do espaço clínico que excita e faz circular, pulsar, expressar a potência 'crianceira' do adulto. Nos encontramos aqui com o que F. Perls et al. (1997) falam sobre a recuperação dos mais belos poderes da vida adulta e que se liga às potências criadoras da criança, tais como: ". . . espontaneidade, imaginação, exatidão da awareness e manipulação." (p. 105). Desta forma, o que se recupera ou, em nossos termos, o que se ativa mais uma vez, conforme nos colocam F. Perls et al. (1997), inspirados na perspectiva de Schachtel, é a "maneira como a criança experiencia o mundo; é libertar não a biografia factual, mas o 'processo de pensamento primário'." (p. 105). Esta libertação do processo de pensamento primário, indicada pelos autores, libera as potênciascapacidades 'crianceiras' que vê o mundo a partir de composições.

Por sua vez, encontramos nas pesquisas de Jakob Von Uexküll (1965) a perspectiva de uma biologia composicional. $O$ autor apresenta a lógica contrapontística da música para pensarmos os processos de combinação entre os seres-indivíduos. Uexküll nos dirá que poderemos ver nas plantas e nos animais a composição da vida se fazendo em contrapontos. Como num duo musical os seres se afetam e se transformam, como se fizessem parte de uma partitura de vida da natureza, se transformando, se reatualizando. Uexküll (1965) propõe que podemos nos inspirar nos contrapontos da música para termos "uma teoria da composição natural" (p. 130). 
Uexküll (1965) se inspira nas paisagens sonoras, promovidas pelos contrapontos melódicos, timbrístricos, rítmicos e harmônicos dos instrumentos musicais, trazendo a imagem de que toda composição musical é constituída por um conjunto de sonoridades que se expressam pelas combinações de determinadas escalas musicais. As combinações entre-melodias se fazem pelos contrapontos: "Esta ligação se faz segundo as regras do contraponto que determinam como pode-se reunir numa mesma partitura os sons de diferentes vozes." (Uexküll, 1965, p. 148). O compositor é livre para ligar todas as melodias.

Uexküll (1965) apresenta a natureza como uma sinfonia em contrapontos melódicos. Assim como as músicas têm as suas partituras, a natureza tem as suas. Neste sentido, o autor nos diz:

"Se na flor não houvesse qualquer coisa de abelha e se na abelha não houvesse qualquer coisa de flor, nunca o acorde seria possível." ( $p$. 151).

A perspectiva da biomusicalidade expressa a vida sendo feita em contrapontos, a partir de 'notas' que se expressam de cada ser na direção de um outro. Assim, o néctar expressa 'notas melódicas sensíveis' que afetam a abelha, pois elas fazem ressonância com o corpo da abelha. Existe algo de abelha na flor e algo de flor na abelha. Elas foram feitas uma para a outra. O pólen que fica nas patinhas e nas asas da abelha é a melodia que será 'escrita' no corpo de uma outra flor. Esta é a potência 'crianceira' da natureza que produz acordes entre as notas (sinais, signos, afetos, emoções) que cada ser expressa na relação com o outro.

Daí a perspectiva da 'biomusicalidade' poder ser a lógica que expressa os signos-sinais portadores de sentidos para os pais e para os bebês e que, com efeito, tenha grau de afetação entre eles. Da mesma maneira que um signo-sinal que a flor expressa afeta uma abelha, um canto de uma mãe poderá ser o signo-sinal-nota-afetiva que tocará a experiência do bebê. A voz da mãe foi feita para o bebê, assim como o bebê foi feito de tal forma para ser tocado pela voz da sua mãe. Sua voz tem a potência de abraçá-lo, mesmo à distância.

\section{Biorritmos contatuais, temporalidades e superfícies contatuais}

"O tempo é que está doente." (Delacroix, 2006, p. 45).

Ao longo do meu percurso, apoiado na Musicoterapia, na Abordagem Gestáltica e nas Filosofias da Imanência, ou seja, naquelas que colocam o foco no papel das experiências e não nas fixações abstratas-conceituais, pude caminhar ao lado de inúmeros casais que 'engravidaram'. Como trabalhador do campo da saúde mental e de consultório particular, foi possível me 'maravilhar' com o fato de 
compor 'biorritmos contatuais vitais' com os casais em suas formas de marcarem os ritmos de suas vidas. Formas de marcarem os ritmos dos contatos que edificam um ambiente vital para o bebê que está sendo gestado. É muito comum receber casais que chegam com uma demanda, desejando reinventar a relação, pois esta é feita por tensões, por dissonâncias nas formas de ver o outro, com muitas projeções de suas heranças familiares que são deslocadas de um sobre o outro. Eles são compositores de partituras de uma vida comum frustrada. F. Perls et al. (1997) apresentam a perspectiva de Otto Rank, afirmando que as formas existenciais que buscam a repetição sem criação seguem a lógica de uma estética frustrada, assim como um artista que repete, no tempo, as suas criações. Segundo Delacroix (2006), no trabalho terapêutico estamos situados numa antropologia do tempo e, com efeito, do tempo que está doente. Desta maneira, as nossas 'patologias' são efeitos das nossas formas de marcar o tempo da vida. Delacroix (2006) nos diz que o tempo doente segue a lógica de Cronos, do tempo cronificado e marcado para o cumprimento do dia a dia, mas, também, para viver a experiência do presente marcada pelas temporalidades do passado, ou seja, de uma vida servil àquilo que já passou. Deste modo, o presente está doente de passado, assim como o presente poderá adoecer pela presença das preocupações com o futuro. Inspirados em Sénèque (2015), diremos que a 'patologia' do presente sofre de um desgosto do passado, tanto quanto do desgosto de um futuro. A 'patologia do presente' advém da perda da capacidade de criação de novas formas de sentir a vida, de se permitir abraçar a vida naquilo que ela nos apresenta aqui-e-agora.

Delacroix (2006), inspirado pelo xamã, afirmará que precisaremos nos ocupar em cuidar e curar o tempo! Liberar o tempo presente para a experiência de construção de partituras vivas de vida com os outros. Poder sentir a vida de tantas maneiras o quanto for possível, conforme Fernando Pessoa (2018). Uma nova sensação é como um afeto-gérmen que pode nos abrir à experiência de novas formas de marcar as pulsações da vida, do ato de viver aqui-e-agora e integrálas ao fundo que nos habita. Poder sentir de maneiras impensáveis. Aqui nos encontramos com a temporalidade de Aion. Temporalidade que expressa como as crianças marcam o tempo de suas experiências. Tempo do devir, tempo do sentir. Temporalidade da experiência onde o adulto, os casais reaprendem a fluir com aquilo que acontece aqui-e-agora: sem representações, sem 'comparamentos'. Eles se lançam na aventura de abraçar a vida e de serem abraçados por ela, tal como Merleau-Ponty (2003) afirma: "Assim o corpo é posto de pé diante do mundo e o mundo de pé diante dele, e há entre ambos uma relação de abraço. E entre estes dois seres verticais não há fronteira, mas superfície de contato." ( $p$. 222). 
Este ato de cuidado com a vida que se faz superfície, nos encaminha à experiência de uma outra forma de temporalidade: nos encontramos com Kairós. Temporalidade do momento oportuno, do bom momento para se agir. Com isso, Hipócrates preconizava, em sua escola de filosofia médica, o cuidado em não se antecipar ao momento da intervenção na relação com o paciente, nem de se perder o bom momento, a ocasião oportuna de agir e de cuidar (Lefève, 2006).

Cumpre notar que este cuidado aos modos de marcação rítmica, cadencial e pulsante das formas de produzir contatos com cada situação, nos encaminha a pensar sobre a qualidade destes mesmos contatos. Cuidado que poderá ser compreendido a partir de um olhar fenomenológico biomusical.

\section{Fenomenologia biomusical, experiência e awareness coletiva}

A ciência pode classificar e nomear os órgãos de um sabiá, mas não pode medir seus encantos.

A ciência não pode calcular quantos cavalos de força existem nos encantos de um sabiá.

Quem acumula muita informação

perde o condão de adivinhar: divinare.

Os sabiás divinam. (Manoel de Barros, 2010, p. 340).

O fenomenólogo francês Merleau-Ponty nos diz que o "corpo é o pivô do mundo" (Delacroix como citado em Peixoto, 2018, p. 23). Corpo sensível, corpo perceptivo, corpo afetante. Corpo que pode nos colocar diante do mundo, diante das situações, diante das 'coisas mesmas', sem cairmos nas representações, nem nos 'comparamentos'.

Podemos desenvolver a potência de nos fazer corpo para o outro... se fazer corpo 'com' o outro... construir superfícies de coexistência (Peixoto, 2018). Aprender a fazer leituras daquilo que acontece coexistencialmente, entre nós e a situação. Inspiramo-nos em Epicuro, Lucrécio e tantos outros filósofos gregos que descreviam fenomenologicamente a vida e as experiências através de poesias (Onfray, 2015).

A fenomenologia biomusical segue a lógica da 'leitura das superfícies contatuais'. Uma fenomenologia dos contrapontos, onde o que se vê e se descreve são efeitos de superfície. Assim, as peles-sonoridades de uma música fazem corpo-acorde com a pele-vibrátil do tímpanocorpo-subjetividade que é percutido por suas modulações sonoras. Poder de sentir o que advém deste processo de coexistência e que se traduz em sensações que escorrem pelo corpo, pelos afetos talvez nunca sentidos, nunca vividos. 
O sentir como tecnologia de produção de conhecimentos afetivos. Spinoza (2007), nesta direção, afirma que a primeira ideia que temos é a ideia do estado do corpo. O sentir como o processo primeiro, processo originário de conhecimentos pré-reflexivos, processo de uma leitura viva das intensidades afetivas. O corpo do bebê é corpoconsciência imediata e sensível para o canto de sua mãe. Seu corpo é, para este canto, superfície de contato... suas sonoridades se inscrevem numa partitura histórica do aqui-e-agora, deixando suas marcas, seus traços, suas mensagens afetivas-sonoras. Eles são, juntos, processo de coexistência. Eles se fazem corpo de um para o outro, tal como a abelha é nota-signo de afetação para a flor e a flor é signo melódico afetante para a abelha: elas se fazem comunhão... se fazem contato...

Desta fenomenologia biomusical dos contatos, temos a imagem de um corpo que empresta ao outro corpo (corpos-olhares, corpossonoros, corpos-semblantes, corpos-desejos...) o lugar de sentidos, 0 habitat para o pertencimento, o lugar de morada, do abraço coexistencial. Passamos a ser leitores e escritores de sensações. Escutamos a potência linguageira dos corpos que escrevem, aqui-eagora, uma nova partitura-superfície de coexistência. Uma sensação, enquanto uma forma afetiva de expressão do corpo, é um modo de ser. Aqui nos inspiramos em Spinoza (2007) para a compreensão fenomenológica das nossas potências de existir. Somos aquilo que podemos a cada instante na relação com os devires do ambientesituação. Daí somos 'arrepio', 'olhar que brilha', 'escuta pulsante', como formas de individuação, de estarmos no mundo, como efeito de coexistência com aquilo que nos afeta, aqui-e-agora. Fomos feitos de tal modo para nos fazermos superfícies de coexistência, de um para o outro.

Inspiramo-nos na filosofia sensível e estética de Merleau-Ponty (1945) que se inclina ao encontro do sentido advindo da abertura das percepções que se orientam na direção de um mundo que está, sempre, 'aí'. Com isso, Merleau-Ponty (1945) nos movimenta ao aguçamento de nossas percepções para habitarmos a vida, o mundo, como uma presença ativa ". . . cujo esforço todo consiste em reencontrar este contato ingênuo com o mundo, para dar-lhe enfim um estatuto filosófico." (p. 01). Merleau-Ponty nos encaminha, mais uma vez, à potência 'crianceira' que nos habita e que pode ser ativada sempre em processos de coexistência. 'Contato ingênuo' movido por uma posição pré-reflexiva, por uma presença no mundo, onde as nossas percepções se abrem a uma posição ativa de receptividade daquilo que 'é'. Contato ingênuo que nos convida a entrar numa íntima relação com a potência linguageira do corpo.

Rehfeld (2013) nos apresenta a perspectiva fenomenológica dos dados intuitivos, vindos das maneiras em que apreendemos o mundo, ultrapassando a razão, strictu sensu, ou o pensamento reflexivo. 
Desta maneira, nos encontramos com a potência de sentir como fundadora de uma leitura do mundo, a partir de conhecimentos préreflexivos. Decorre disso a exploração destes dados intuitivos e sensíveis como conhecimentos não-substantivados, colocando-se em suspensão toda forma de julgamento, de preconceitos, de hipóteses. Deixamos de acumular muita informação para não perder o condão de 'adivinhar' sensualmente, afetivamente o que se passa 'aí'. Pois não há régua da ciência que possa medir o que se passa nestes processos de coexistência.

O papel da experiência é fundamental nesta leitura do mundo. Merleau-Ponty (1945) nos dirá que não somos simples objetos da biologia, da psicologia, ou mesmo, da sociologia, nem nos reduzimos ao universo da ciência. Ele afirmará que: "Tudo aquilo que sei do mundo, mesmo por ciência, eu o sei a partir de uma visão minha ou de uma experiência do mundo sem a qual os símbolos da ciência não poderiam dizer nada." (Merleau-Ponty, 1945, p. 03). A vida, o mundo, as situações são as nossas experiências primeiras. As experiências nos dão acesso aos conhecimentos primeiros: os conhecimentos advindos do corpo, dos processos de intercorporeidade e de intersubjetividade. Vale ressaltar sobre o grande papel das experiências para a Gestalt-Terapia, para a Musicoterapia e para as Filosofias da Imanência: todos estes campos têm 'apetite' de experiências.

Apresentaremos abaixo os princípios que serão fundamentais para a perspectiva de uma Fenomenologia biomusical, das experiências, dos 'biorritmos contatuais vitais' e, com efeito, de uma awareness coletiva, advinda da relação entre os pais e entre estes e os bebês.

\section{a) Princípio contatual: penetração entre mundos}

Minkowski (2013), ao propor o conceito de contato vital, apresenta o princípio de penetração. Esse sendo fundamental para que o contato emerja. O princípio de penetração pode ser sentido quando somos penetrados e penetramos uma dada situação-experiência. Quando contemplamos um entardecer, somos penetrados e penetramos esta experiência. Passamos a devir-entardecer. Sentimos que fazemos parte desta paisagem. A paisagem se faz corpo para o olhar... o olhar se fazendo corpo para acolher as imagens e melodias das cores do entardecer. Olhar-entardecer se fazem corpo de um para o outro.

Das experiências onde sentimos que somos penetrados por elas e, a um só tempo, a penetramos, emergem as superfícies-fronteiras contatuais como espaços de relação entre-mundos, entre 0 organismo-ambiente. Experiências de uma sexualidade do contato, de uma sensualidade das percepções, de uma consciência afetiva, vertida e inclinada àquilo que é identificado como nutritivo (Peixoto, 2015). 
Um ponto fundamental: a penetração entre mundos é acompanhada de uma potência vital que deverá ser conhecida no trabalho com os pais na relação com os bebês: a potência de ir em direção a algo advindo do ambiente e de se conectar. Vale destacar a relação de interpenetração das experiências musicais entre a mãe e o bebê que está sendo gestado. Barcellos (como citado em Negreiros, 2008, p. 18) nos dirá que "o som nos acompanha desde a vida intra-útero até a nossa morte, e embora muitas vezes não percebamos, fazemos parte de uma paisagem sonora que ao mesmo tempo nos envolve e contamina". Experiência de penetração entre-mundos, mediada pela experiência biomusical. Diremos que os ambientes sonoro-afetivospercussivos-musicais se constituem como o berço primordial, proporcionando o abraço, o colo matricial que pulsa do fundo constituinte de todos nós o afeto de pertencimento. Pertencimento que se tece por processos biomusicais de coexistência.

\section{b) Potência vital e desejante}

$\mathrm{Na}$ criação de biorritmos contatuais vitalizados, precisaremos conhecer quais são as potências-capacidades dos pais de se inclinarem àquilo que vem do mundo do outro. A curiosidade sobre o que advém do ambiente do outro é um dado importante nesse trabalho. Conhecer se os pais se inclinam ao mundo do outro é seguir a lógica da biomusicalidade, que apresentamos na primeira parte do trabalho.

Os psicanalistas pré-objetais, tais como Michael Balint, Imre Hermann e Leopold Szondi (como citado em Robine, 1998) nos falam sobre a capacidade imanente dos bebês quando se lançam àquilo que vem do mundo. Decorre daí que este 'desejo de ir em direção' a 'algo' é um fenômeno de campo, é um fenômeno situacional, pois algo do ambiente precisou ter força de afeto, força de afecção para tocar e movimentar a curiosidade, o interesse, o apetite de se ligar ao que vem do mundo, do outro, da situação-ambiente. Fenômeno desejante originário e que habita os adultos. Acordar este fenômeno desejante nos pais é um dos grandes desafios.

O terapeuta que trabalha com a perspectiva fenomenológica biomusical precisará desenvolver capacidades de uma Scientia Patibilis Natura, ou seja, de uma Ciência da Alma Sensível! Será estar aware dos ritmos, das cadências, das pulsações daquilo que impulsiona as palavras dos pais, ou seja, do mundo implícito que faz corpo neste ambiente composto por todos. Experiências onde as 'palavras do corpo', esta potência linguageira pré-individual (Simondon, 2005) e pré-reflexiva, ganham vida criançando através das composições entre pais, bebês e terapeuta. 


\section{c) Princípio da simpatia-ressonância}

No período da gestação, começamos juntos a desenvolver as capacidades de perceber os detalhes das emoções que vêm do pai e da mãe. Nessa fase, os pais passam a perceber as 'notas melódicas emocionais' que nascem deste campo. É a experiência onde nos encontramos com o Id da situação (Alvim, 2016; Robine, 2004, 2012). Vivemos juntos a experiência de perceber os 'dados' que advêm de um fundo comum que é nascido do casal e do ambiente sonoro-percussivo-musical. Um ambiente sempre imprevisível e inédito. 'Algo' (Id) dimana deste fundo comum, onde as sonoridades das músicas são cantadas ou improvisadas no piano, no violão, com percussões que pulsam e movimentam a função Id do Self de cada um, inclusive do terapeuta. Do processo de interpenetração e percussões entre as funções Id, singulares a cada um, temos a emergência de afetos, emoções, imagens, melodias, movimentos, lembranças e tantos outros 'dados' que vêm se compor 'biomusicalmente' neste espaço estético de relação.

Experiência que se dobra e se desdobra em tantas possibilidades, a partir do processo de intercorporeidade e de intersubjetividade que entrelaça nossos mundos. Espaço estético-poiético, espaço onde sentimos, juntos, que uma história está a se tecer. História que não é contada com palavras, mas sim com os afetos, com as emoções, com os semblantes e com tantas outras 'notas afetivas' que compõem cada um e este ambiente. Esta é a experiência onde se bordam as terceiras histórias pré-individuais ou pré-reflexivas entre casais, bebês e terapeuta.

Um de frente para o outro, o olhar penetrando o olhar do outro. Perceber os detalhes do olhar que toca. Tocar o olhar do outro com o seu olhar. Perceber os micromovimentos que aparecem no semblante. Poder ficar no silêncio de um contato de onde se experimentam os detalhes daquilo que não é vivido no cotidiano de suas vidas. Poder compreender o outro por puras sensações. A música os envolve, dando continente a este momento. O som do piano, a um só tempo, envolve, dá continente e penetra seus mundos. A mão do marido toca o rosto de sua mulher. Ela sorri levemente. Os olhos em contato. De longe sinto que algo nasce neste campo de experiências afetivas sensíveis. Algo de 'simpático e ressonante' faz acorde neste instante. $O$ que vem do fundo de cada um faz acorde, buscando se ligar, buscando durar no tempo. O tempo flui... o espaço da relação nasce. Novas temporalidades acordam e se desviam de suas crônicas repetições. Eles aprendem a ser parteiros de sensações, de um para o outro e para o gérmen de vida que habita a mulher.

Diremos, ainda, que a potência crianceira advinda das experiências de simpatia-ressonância se ligam à potência 'bebê' que trazemos em 
nós. Potência curiosa e travessa que vai em direção aos estímulos do ambiente.

\section{d) Princípio da sincronia}

Caminhar juntos e docemente pela grande sala do atelier. De olhos fechados, de mãos dadas, sentindo e acompanhando as cadências e pulsações da música. Os pés tocando o chão como passos de Tai Chi Chuan. Os calcanhares tocam a terra como se abrissem uma pequenina fenda. Imaginam uma semente que cai na fenda. $O$ movimento das plantas dos pés enterrando levemente a semente sob a terra. Andam como numa dança, sentindo as cadências que os dois, juntos, são capazes de compor com a música. Todos, casal e terapeuta, formam um corpo-organismo-ambiente onde o cuidado é tecido por melodias de gestos, toques, passos, abraços, suspiros, arrepios que fazem o corpo 'gozar' pelos poros. A sensualidade do contato advém da sincronia dos mundos que compõem o parto de uma relação antes nunca vivida. Eles pensam através dos poros, pensam através dos gestos, dos movimentos. Reflexões sensíveis sem palavras. Eles desenvolvem, paulatinamente, a leitura dos afetos de vitalidade (Stern, 1985). Esses afetos estão presentes em todos nós, desde bebês. Um bebê sente em seu corpo afetos de crescendos, de diminuindos, de excitações que podem vitalizá-lo, expressando prazer, ou, ao contrário, desvitalizá-lo. São afetos que expressam no corpo o sentido de expansão, de contração, de pulsações, de cadências mais apressadas que podem ser vistas pelos movimentos dos gestos, da forma de se expressar com a voz, dentre infinitas possibilidades expressivas corpóreas. Os afetos de vitalidade advêm de um fundo linguageiro do corpo-organismo.

Fazemos um 'ritornello', neste momento, reapresentando o que $F$. Perls et al. (1997) disseram sobre o trabalho de recuperação daquilo que é uma das mais belas potências que o adulto pode ativar na relação com o ambiente: os poderes da criança, tais como a curiosidade, a imaginação criadora, a espontaneidade, a awareness lançada ao que produz apetite, a manipulação criadora das matériasprimas que o ambiente oferece no aqui-e-agora da experiência. Os adultos se encontrando, mais uma vez, com uma forma de fazer a leitura da vida e das experiências: fazendo comunhão com o que está diante de si, sem cair nas representações ou nas suas formas crônicas de agir e pensar por 'comparamentos', como nos ensinou Manoel de Barros (2003). Será reaprender ou aprender a fazer, pela primeira vez, a 'transfusão da natureza e comunhão com ela'.

Esta é uma experiência que nos fala sobre a invenção de novos ritmos e novas cadências nas formas da relação se contatar. Temos uma rítmica dos contatos, uma dança contatual onde os mundos buscam não se apressar. O movimento de um se ligando ao movimento do outro. A emoção de um se ligando à emoção do outro. 
Eles se encontram através de uma temporalidade simpáticoressonante, pois desenvolvem a capacidade de sentir os ritmos dos afetos que vêm um do outro. Buscam se ajustar criadoramente ao inesperado que vem do outro e do ambiente sonoro-musical. Seus corpos-afetos entram em devir com o devir do ambiente plástico.

O ambiente sonoro-afetivo-percussivo-musical os lança aos movimentos incertos das correntezas do devir. Eles aprendem a entrar nas correntezas das imprecisões, das incertezas dos movimentos, para onde este ambiente flutuante poderá levá-los. Inspirados em Canguilhem $(1978,2012)$, diremos que se os campos de experiência nunca são os mesmos, isso se dá pela 'infidelidade do meio'. Eles desenvolvem a capacidade de se ajustarem às imprecisões que o ambiente Ihes proporciona. Eles devém-dançarinos de um presente aberto às novidades. 'Aprendem a criançar, mais uma vez'!

\section{e) Princípio da empatia}

Ir ao mundo do outro, sem julgamentos, sem preconceitos. Simplesmente se sentir pertencente ao outro mundo, numa rítmica de uma dança contatual através de linhas e direções não preestabelecidas. Esta rítmica se faz em ato, sem ensaios, feita no momento mesmo da experiência. Com isso, esta dança contatual se tece a partir de uma fenomenologia contatual em ato. Desenvolver capacidades de fazer a descrição daquilo que acontece sem palavras, mas a partir de um mundo gestual gestado pela sensualidade dos movimentos dos corpos. Uma escrita feita por gestos, envolvida pelo ambiente sonoro-musical. Uma comunicação pré-reflexiva, onde o presente é habitado por uma língua que nos habita. Língua herdada dos primeiros homens e mulheres deste planeta. Escrita feita por signos afetivos e sensoriais. O canto devém da palavra afetiva, palavra poética, palavra sentida.

Compreender o outro sem palavras: estar em pathos, estar na sensibilidade do outro, estar na emoção do outro (Strauss, 2000). Assim, o casal se envolve com esse ambiente sonoro-percussivomusical contatual onde conseguem, muitas vezes, compreender o que se passa na experiência do outro, mesmo que não se diga uma só palavra. Vale enfatizar que a palavra contato advém do verbo latino contingere, sendo formada por tangere que significa: tocar, palpável, tangível (Maldiney, 1990). Curiosamente, a palavra 'tango' se origina, em uma de suas acepções, da palavra tangere. A palavra 'tango' tem a sua origem, por sua vez, na língua africana, significando "lugar de encontro". Lugar onde os africanos dançam, bailam em contatos pulsantes e sensuais. Lugar onde se fazem corpo-desejante-pulsante de uns para os outros. Lugar estético onde a poesia da relação se faz por percussões de afetos múltiplos. 
Os casais passam a ingressar, paulatinamente, neste espaço de relação, espaço de contatos sensuais. Ir ao mundo do outro numa rítmica dos contatos, numa escrita afetiva feita por linhas, direções, gestuais não preestabelecidos. Os sentidos produzidos por este ambiente 'pático' (Strauss, 2000), sensível, advém desta consciência plástica, desta consciência mutual, conforme nos diz Laura Perls (2001). Uma consciência coletiva advém do movimento de ir ao mundo do outro, de poder senti-lo sem julgamentos, nem preconceitos. Consciências que se ligam formando uma 'terceira consciência', como uma consciência de campo, uma consciência que não se explica pela consciência de um ou de outro. Ela é efeito de um processo de composição entre consciências que se ligam à potência crianceira da situação. Consciências coletivas, consciências mútuas que são movidas pela capacidade comum de se ajustarem criadoramente ao que acontece, aqui-e-agora, singularmente e em ato.

Desta maneira, uma awareness coletiva se borda. É por meio do bordado do contato dado através dos fios dos afetos, dos interesses, dos gestos, dos movimentos, na relação com as cadências, com as pulsações, com as sonoridades da música, também construídas e compostas em ato, que se gesta essa awareness coletiva. Awareness filha das suas potências de devirem crianças, de uma 'potência crianceira' que dá formas inéditas ao que acontece. Neste sentido, pude ver muitos pais e mães bailando e cantando neste espaço de contigere, espaço do 'tango', espaço ritual banhado por envelopes sonoros-percussivos-afetivos-musicais. Eles se fazem corpo-canto, corpo-voz, de um para o outro, para gestar uma temporalidade empática de cuidado.

Alvim (2017) afirmará que a empatia se define como uma operação do corpo. Operação que permite uma comunicação silenciosa e sensível, vindo reconhecer o mundo do outro numa dimensão em que ainda não se consegue traduzir de forma objetiva em palavras. Esta é uma comunicação dos afetos, ou seja, das formas contatuais em que terapeuta e 'paciente', juntos, podem desenvolver. $O$ ambiente sonoro-musical proporciona experiências únicas, sobretudo, quando o terapeuta desenvolve capacidades de poder estar em 'pathos', na experiência de poder sentir os afetos que advém de uma pessoa. Esta é a experiência onde a temporalidade do sentir advém da temporalidade do devir, temporalidades proporcionadas por todo este ambiente. Estar em 'pathos' é seguir esta operação do corpo que Alvim (2017) nos fala. Este é o processo de intercorporeidadeintersubjetividade escrito pela potência linguageira do corpo. Potência escrita por signos afetivos-sensoriais biomusicais. 


\section{f) Princípio da sintonia}

Minkowski (2013) nos dirá que a sintonia é o princípio que nos permite vibrar em uníssono com o ambiente. Vale ressaltar sobre as funções do ambiente sonoro-percussivo-musical e os efeitos de subjetividade que ele proporciona. A musicoterapeuta francesa Edith Lecourt (como citado em Anzieu, 2013) apresenta a bela perspectiva do envelope sonoro-musical. $O$ envelope sonoro-musical contagia a todos. A sonoridade que envolve com a sua ausência de concretude, de tangibilidade, toca, sendo 'tocante', sendo um fenômeno sensível que ganha a sua tangibilidade através dos afetos que atravessam este campo complexo. Envelope sonoro-musical que possui a potência de produzir envelopes de afetos tangíveis-tocantes.

Desta forma, como um útero materno, o espaço de relação construído pela potência sonoro-musical produz inúmeras funções, inspirando-nos aqui em Didieu Anzieu (1995, 2013), através de sua perspectiva do 'Eu Pele' e dos 'Envelopes psíquicos', modificados para o nosso interesse: 1 - A função de manutenção da existência e do senso de existência: da vida subjetiva-implícita, através dos contornos e do abraço que as polifonias sonoras e rítmicas produzem com os movimentos e intensidades musicais; 2 - a função de contenção: 0 abraço dos envelopes sonoro-musicais produzem envelopes táteis pelo toque do som, pela extensão do corpo, pois assim como a pele envolve o corpo, os envelopes sonoro-musicais envolvem quem se afeta por eles; 3 - a função de para-excitação: envolver-se com os envelopes sonoro-musicais será poder encontrar territórios de proteção junto com os outros, protegendo-se neste espaço comum de pertencimento, feito pelas texturas sonoromusicais; 4 - função de individuação: os envelopes sonoromusicais, a um só tempo, dão continente, assim como mantém, conservam e, com efeito, movimentam aquilo que já está individuado para que se ganhe outras individuações, novas gestalten; 5 - a função de intersensorialidade: o fato de cantar, de liberar as potências pré-individuais, pré-reflexivas, produz o agenciamento sensual, estético, sensível para a construção de uma consciência sensorial comum que se encarna como corpo-sonoro-da-relação; 6 função de superfície de apoio da excitação afetiva: as vibrações sonoro-musicais liberam e excitam a imaginação criadora, produzindo ajustamentos criadores em meio ao que acontece. As partes já individuadas, e que fazem parte de cada um, podem se transindividuar em novas possibilidades, atualizando-se pelos modos de afetação entre-corpos-sonoro-musicais; 7 - função de inscrição dos traços sensoriais táteis-sonoros: a pele ganha 0 envolvimento das peles-sonoras, peles-musicais, peles-desejos, peles-afetos, peles-sonhos, peles-falas, peles-danças. Cada um pode se sentir 'vestido' e 'revestido' pelos traços que são inscritos nas superfícies contatuais que nascem deste território-ambiente. Algo 
nasce deste campo sonoro-musical complexo de onde os sentidos nascem pelo corpo, pelo processo de intercorporeidade e de intersubjetividade que dá novos movimentos ao indivíduo-situação (Peixoto, 2018).

Estas funções dos envelopes sonoros-afetivos contribuem para a construção dos contatos vitais. O contato devém vital quando os campos de experiência proporcionam o desenvolvimento dos princípios da penetração, da simpatia-ressonância, da empatia, da sincronia (temporalidade simpático-ressonante-empática), da sintonia. São princípios de uma biomusicalidade construída sempre de forma singular. Nunca predeterminada, planejada. Todos nós nos gestamos neste espaço biomusical. Entramos em sintonia quando passamos a entrar na temporalidade do devir, na temporalidade do sentir. Transindividuamo-nos (Simondon, 2005) a partir da conexão das consciências sensíveis e imediatas que acompanham os movimentos de transformação que ocorrem em cada um de nós, inclusive no terapeuta que é parte deste ambiente complexo. Assim, os pais aprendem a acompanhar as 'notas-signos-sinais' advindas do bebê. Eles conseguem, pouco a pouco, 'ler' os afetos do bebê. É muito comum que, com a música, sobretudo, a partir de alguns meses de gestação, o bebê faça movimentos quando as vibrações do canto da mãe o afetam. Depois, com as sonoridades-vibrações do ambiente-sonoro-percussivo-musical, estes 'signos-notas-sinais' afetivos do bebê se tornam parte de nossos encontros. Somos parteiros de afetos, antes do nascimento.

O mais lindo acontece quando os pais trazem os bebês após o nascimento. É de arrepiar quando toco docemente o piano ou o violão. É frequente os bebês buscarem o ambiente sonoro-musical, direcionando a cabeça na direção da música. Monteiro (2011) nos fala sobre esta busca do bebê para a fonte sonora. Negreiros (2008) nos apresenta as pesquisas de Ockelford e outros que demonstram que os bebês com menos de 24 horas de nascidos buscam a orientação da voz materna. Negreiros (2008), apoiada em Aberastury e Alvarez de Toledo, ainda nos diz que a bela experiência da voz materna que afeta a vida precoce de um bebê pode ser considerada como o "leite que entra pelos ouvidos" (p. 22). O leite-sonoro-percussivo-afetantemusical alimentando a subjetividade do bebê muito antes do seu nascimento. Diremos, inspirados em Benenzon (1987) e Altshuler (1954), que uma Identidade Sonoro-Afetiva-Anímica-Musical, a nosso ver, 'Emergente e Coletiva', se constitui através da atualização da história sonoro-musical dos pais. Esta fazendo parte da história sonoro-musical nascente dos filhos e que se liga à função personalidade coletiva-grupal. Uma identidade que não se explica a partir de uma 'entidade fixa' e imutável. Mas sim, a partir de constelações morfo-afetivas advindas dos ambientes sonoro-afetivospercussivo-expressivos-musicais entre pais, bebês e terapeuta. 
Id-entidades sonoras-afetivas-percussivas-musicais brotam deste campo de experiências. Sempre algo indeterminado, jamais préestabelecido, dimana destes campos de afetações. Experiências onde podemos nos encontrar, mais uma vez, com o Id da situação (Alvim, 2016; Robine, 2004) e, assim, sermos envolvidos, envelopados pelos 'dados' afetivos que nascem das percussões entre as funções Id do self singulares a cada um. Percussões afetivas que tocam os 'fundos matriciais' singulares para a emergência, sempre inédita, de uma matéria-prima sensível, 'pática', passional e estética que ganha forma a partir deste fundo comum, nascido em ato. Fundo comum germinador de novos mundos e de novas formas de contatar. Fundo comum-usina de uma Gestalt-coletiva-emergente que pulsa destes campos de afetações.

Fazemos acordes de consciências, temporalidades, histórias, desejos, afetos e sensações. Compomos acordes de existências que se fazem corpo coletivo a partir deste fundo comum que libera as id-entidades sonoro-afetivas-percussivo-expressivas-musicais. Criamos um microcosmo (F. Perls, 1988) neste espaço clínico, espaço da relação, gestado pela awareness coletiva que nos liga, nos une, fazendo-nos mais humanos. Afinal, a palavra 'humano' advém do latim 'humanus', também relacionado a 'homo', homem, húmus. Devimos terra sagrada para gestar e acolher o ser que nasce como broto de vida e vibra com seus afetos para fazer parte das partituras de vida que compomos a cada experiência. Devimos, todos, parteiros de afetos, parteiros de nós mesmos. Espaço clínico, espaço da relação, espaço do sagrado, espaço de afetações contrapontísticas, espaço da musicalidade da vida, espaço biomusical.

\section{Conclusão}

A aposta numa clínica apoiada na aliança entre a Gestalt-Terapia, a Musicoterapia e as Filosofias da Imanência para a produção do cuidado entre pais e bebês, nos lança às experiências onde se desenvolvem capacidades biomusicais de 'leitura' e 'compreensão' de outros territórios de sentidos. É uma aposta na produção de 'lentes de ver' e 'lentes de sentir', aquilo que se passa no outro e em si mesmo, a partir dos contrapontos de signos-sinais-notas afetivos que nascem e transbordam das experiências vividas em ato. É poder compreender para além das palavras. É poder compreender sentindo aquilo que é da ordem do intangível e que se torna tangível, através dos sentidos afetivos que tocam, afetam, como experiências 'tocantes'. É poder ser abraçado pelas experiências e abraçá-las com aquilo que vem do fundo de cada um e que devém figura contatual que se forma e se borda nas inéditas superfícies de coexistência. É poder se abrir às experiências emergentes do fundo comum que 
germina as id-entidades sonoro-afetivas-percussivo-expressivasmusicais que nos retiram todos, inclusive o terapeuta, das crônicas formas de contatar e de compor os contatos. Pais que buscam encontrar novas cadências, ritmos e pulsações nas suas formas de se afetarem, produzindo efeitos na musicalidade da vida dos seus filhos. Abertura feita a partir de uma Scientia Patibilis Natura, de uma Ciência da Alma Sensível. Desenvolvimento de novos olhares para o cuidado estético advindo de uma fenomenologia biomusical. Pais, bebês e terapeuta que aprendem juntos, sempre mais uma vez, a entrar nas temporalidades do devir, transformando-se, a partir deste campo de experiências vitais... aprendem a caminhar juntos na temporalidade da vida, sempre incerta e a ser descoberta... ingressam no processo de reinvenção de si e da relação, numa sempre nascente temporalidade das sensualidades, temporalidade do cuidado, temporalidade do devir, temporalidade do sentir.

\section{Referências}

Altshuler, I. (1954). The Past, Present and Future of Musical Therapy. In E. Podolsky (Ed.), Music Therapy (pp. 28-30). New York: Philosophical Library.

Alvim, M. (2016). Le ça de la situation, fond commun de l'expérience. In J. M. Robine (Ed.), Self: Une Polyphonie de Gestalt Thérapeutes Contemporains (pp. 323-339). Bordeaux: L'exprimerie.

Alvim, M. (2017). Transtorno bipolar, temporalidade e conexão com o outro: reflexões preliminares. In L. M. Frazão \& K. O. Fukumitsu (Eds.), Quadros Clínicos disfuncionais e GestaltTerapia (pp. 45-74). São Paulo, SP: Summus Editorial.

Anzieu, D. (1995). Le Moi-Peau. France: Dunod.

Anzieu, D. (2013). Les Enveloppes Psychiques. France: Dunod.

Barros, M. (2003). Memórias inventadas. São Paulo, SP: Planeta.

Barros, M. (2010). Poesia completa. São Paulo, SP: Leya.

Benenzon. R. (1987). O autismo, a família, a instituição e a musicoterapia. Rio de Janeiro, RJ: Enelivros.

Canguilhem, G. (1978). O Normal e o Patológico. Rio de Janeiro, RJ: Forense Universitária.

Canguilhem, G. (2012). O Conhecimento da Vida. São Paulo, SP: Forense Universitária.

Delacroix, J. (2006). La Troisième Histoire. Patient-psychothérapeute: fonds et formes du processus relationnel. France: Dangles.

Lefève, C. (2006). La philosophie du soin. La Matière et l'esprit, Médicine et Philosophie, 1(4), 25-34.

Maldiney, H. (1990). Esthétique et contact. In J. Schotte (Ed.), Le contact (pp. 195-220). Bruxelles: De Boeck-Wesmael. 
Merleau-Ponty, M. (1945). Phénoménologie de la Perception. France: Éditions Galimard.

Merleau-Ponty, M. (2003). O visível e o invisível. São Paulo, SP: Editora Perspectiva.

Minkowski, E. (2013). Le temps vécu. France: Presses Universitaires de France.

Monteiro, N. (2011). Quadro do desenvolvimento Audiomusicoverbal infantil de zero a cinco anos para a prática de Educação Musical e Musicoterapia. Revista Brasileira de Musicoterapia, 11(13), 98-116.

Recuperado

http://www.revistademusicoterapia.mus.br/wpcontent/uploads/2016/10/5-Quadro-do-desenvolvimentoAudiomusicoverbal-infantil-de-zero-a-cinco-anos-para-apr\%C3\%A1tica-de-Educa\%C3\%A7\%C3\%A3o-Musical-eMusicoterapia-1.pdf

Negreiros, M. (2008). Musicoterapia e Aleitamento Materno (Dissertação de Mestrado). Faculdade de Medicina, Programa de Pós-graduação em Clínica Médica (Saúde da Criança e do Adolescente), Universidade Federal do Rio de Janeiro, Rio de Janeiro, RJ, Brasil.

Onfray, M. (2015). Cosmos. Une ontologie matérialiste. France: Flammarion.

Peixoto, P. (2015). De l'esthétique de la ville à la gestaltcommunauté. Pour un ajustement créateur citadin. Gestalt, 1(46), 21-32. Recuperado de https://www.cairn.info/revuegestalt-2015-1-page-21.htm

Peixoto, P. (2018). Gestalt-Terapia \& Contatologia: filosofia, arte e clínica dos processos de formação das superfícies contatuais. Macaé, RJ: Paulo-de-Tarso Edições.

Perls, F. (1988). A Abordagem Gestáltica e Testemunha Ocular da Terapia. Rio de Janeiro, RJ: LTC - Livros Técnicos e Científicos Editora.

Perls, F., Hefferline, R., \& Goodman, P. (1997). Gestalt-Terapia. São Paulo, SP: Summus Editorial.

Perls, L. (2001). Vivre à la frontière. Bordeaux: L'exprimerie.

Pessoa, F. (2018). Livro do Desassossego. Versão Kindle. Rio de Janeiro, RJ: Nostrum Editora.

Rehfeld, A. (2013). Fenomenologia e Gestalt-Terapia. In L. M. Frazão \& K. O. Fukumitsu (Eds.), Gestalt-Terapia: Fundamentos Epistemológicos e Influências Filosóficas (pp. 24-33). São Paulo, SP: Summus Editorial.

Robine, J. M. (1998). Gestalt-Thérapie: la consctuction du soi. France: Édition l'Harmatan.

Robine, J. M. (2004). S'apparaître à l'occasion d'un autre. Etudes pour la psychothérapie. Bordeaux: L'exprimerie. 
Robine, J. M. (2012). Le Changement Social Commence à Deux. Essais et Conférences. Bordeaux: L'exprimerie.

Sénèque. (2015). École du Stoïcisme. Oeuvres Complètes. France: Arvensa Éditions.

Simondon, G. (2005). L'individuation à la lumière des notions de forme et d'information. France: Millon.

Spinoza, B. (2007). Ética. Edição bilíngüe: latim-português. Belo Horizonte, MG: Autêntica Editora.

Stern, D. (1985). The interpersonal world of the infant: A View from Psychoanalysis and Developmental Psychology. New York: Basic Books.

Strauss, E. (2000). Du sens des sens. France: Éditions Jérôme Millon. Uexküll, J. V. (1965). Mondes Animaux et Monde Humain - suivi de la Théorie de la Signification. France: Éditions Denoël.

\section{Endereço para correspondência \\ Paulo-de-Tarso de Castro Peixoto}

Rua Luiz Belegard, 174, sobrado, Centro, CEP 27913-260, Macaé - RJ, Brasil

Endereço eletrônico: paulo.tarso.peixoto@gmail.com

Recebido em: 13/10/2019

Reformulado em: 25/02/2020

Aceito em: 25/02/2020

\section{Notas}

* Pós-doutorando em Psicologia (UFRJ). Pós-doutorado em Filosofia UFRJ e Paris XII. Mestre e Doutor em Psicologia (UFF). Graduado em Filosofia UNIMES e em Musicoterapia CBM (RJ).

Este artigo de revista Estudos e Pesquisas em Psicologia é licenciado sob uma Licença Creative Commons Atribuição-Não Comercial 3.0 Não Adaptada. 